\title{
Managing Business-to-Business Customer Relationships Following Key Contact Employee Turnover in a Vendor Firm
}

Customers form relationships with the employees who serve them as well as with the vendor firms these employees represent. In many cases, a customer's relationship with an employee who is closest to them, a key contact employee, may be stronger than the customer's relationship with the vendor firm. If the key contact employee is no longer available to serve that customer, the vendor firm's relationship with the customer may become vulnerable. In this article, the authors present the results of two studies that examine what business-to-business customers value in their relationships with key contact employees, what customers' concerns are when a favored key contact employee is no longer available to serve them, and what vendor firms can do to alleviate these concerns and to retain employee knowledge even if they cannot retain the employee in that position. The studies are based on a discovery-oriented approach and integrate input from business-to-business customers, key contact employees, and managers from a broad cross-section of companies to develop testable propositions. The authors discuss managerial and theoretical implications and directions for further research.

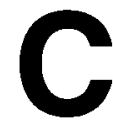
ustomers frequently form relationships with the employees with whom they interact, as well as with the firms these employees represent. The employees who are closest to the customer, whom we term key contact employees, include the insurance agent who calls on a business, the lead architect on a design project, or the certified public accountant from an accounting firm that does the company's books (Stanley 1985). In many cases, customers' relationships with the vendor firm's key contact employees are stronger than their relationships with the firm itself (Czepiel 1990; Gwinner, Gremler, and Bitner 1998). Vendor firms encourage the relationship-building efforts of their employees with business-to-business customers, as well as with end consumers (Cravens 1995; Dwyer, Schurr, and Oh 1987; Weitz and Bradford 1999), because they view these relationships as means to strengthen the firms' relationships with the customers.

When a vendor firm's key contact employee is no longer available to serve the customer, the loss may fundamentally alter the firm's relationship with the customer. American Express estimates that, on average, $30 \%$ of a financial advisor's clients would move with their advisor if he or she were to leave the firm (Tax and Brown 1998). Even if the customer is unwilling or unable to switch to a competitor in the short run because of switching costs and contractual obligations, in the long run, the loss of a favored key contact employee still may be a catalyst for the customer to reevaluate the business relationship with the firm (Anderson and

Neeli Bendapudi is Assistant Professor of Marketing, and Robert P. Leone is Professor and Berry Chair in Marketing, Fisher College of Business, The Ohio State University
Robertson 1995; Duboff and Heaton 1999), making the customer less open to building additional bonds with the firm and/or more open to moving to a competitor over time.

Historically, firms have dealt with this issue by relying on retention and noncompete agreements. Retention emphasizes building employees' organizational commitment and preventing turnover (Gould 1979; Lee and Maurer 1997). However, in a booming economy and tight labor market, some employee turnover is inevitable. Furthermore, the customer experiences turnover in the key contact employee position not only when the employee leaves the firm but also when the employee is transferred or promoted within the firm. Noncompete clauses and contracts prohibit employees from working for direct competitors to minimize the potential for customer loss following the loss of an employee. However, courts are striking down these clauses as restricting trade (Stafford 1998), and several states have enacted laws to limit or eliminate such clauses (Singleton 1997). Because of these economic and regulatory realities, vendor firms must find other solutions to address potential negative responses from customers in any situation in which their employees are unable to continue to serve customers.

Despite its managerial relevance (Buss 1999; Slater 1998), there has been little academic attention to what happens to the vendor firm-customer relationship when there is key contact employee turnover. We address the gap in academic literature by examining through two studies (1) customer responses to key contact employee turnover and (2) the strategies firms can use to reduce the vulnerability of the firm-customer relationship in this situation. We adopt a discovery-oriented approach, drawing on the input of business practitioners. We then integrate their input with extant literature to develop a theoretical model and research propositions. 


\section{Study 1: Business-to-Business Customers' Concerns About Key Contact Employee Turnover in Vendor Firms}

\section{Conceptual Background and Research Questions}

In studying business-to-business customer relationships, several authors have made the case for dealing with customer relationships with the firm and its key contact employee as distinct but interrelated constructs (Barnes 1997; Weitz and Bradford 1999). Much of the literature on customer relationships with a vendor firm's employees has focused on understanding the employee characteristics that contribute to strong customer relationships such as familiarity (Brown 1995), expertise (Brown and Swartz 1989), customization (Smith and Smith 1997), similarity (Crosby, Evans, and Cowles 1990), empathy (Pilling and Eroglu 1994), likability (Jones et al. 1998), trust (Doney and Cannon 1997), and power within the organization (Moorman, Deshpandé, and Zaltman 1993). These relationships result in positive emotional ties (Beatty et al. 1996; Price and Arnould 1999) and greater likelihood of the customer continuing to do business with the firm (Seabright, Levinthal, and Fichman 1992).

Studies of the vendor firm-customer relationship have focused on the firm characteristics that result in strong ties with customers (Brown 1998), such as familiarity (Yoon, Guffey, and Kijewski 1993), financial soundness (Hammond and Slocum 1996), leadership competence (Petrick et al. 1999), and corporate social responsibility (Brown and Dacin 1997). Relationships with firms affect customers' product responses (Brown and Dacin 1997), as well as business partners' interorganizational relationships (Dollinger, Golden, and Saxton 1997).

Despite the interrelationships between the two foci of customer relationships-firms and their employees-most studies focus only on one relationship level, either the relationship with the employee (Crosby, Evans, and Cowles 1990) or the relationship with the firm (Morgan and Hunt 1994). Scant attention has been paid to customers' simultaneous relationships with both targets: key contact employees and the firms they represent (Doney and Cannon 1997).

We have identified only four studies that simultaneously examine the relationships of the customer to the employee and the vendor firm. Doney and Cannon (1997) report differential antecedents and consequences of trust in the firm versus trust in its salesperson in a business-to-business context and find that customers' trust in the firm directly affects their intentions to do business with it, whereas trust in the salesperson has an indirect effect through trust in the firm. Macintosh and Lockshin (1997) examine customers' relationships with stores and their employees and find that strong relationships with specific employees have a positive effect on the customers' attitudes toward the store. Brown (1995) reports that there is greater correspondence between evaluations of the suppliers and the suppliers' sales forces when customers evaluate vendors with whom they are familiar than when they evaluate vendors with whom they are less familiar. Reynolds and Beatty (1999), in a study of retail consumers, find that loyalty to the salesperson leads to several firm-level benefits, such as increased spending and positive word of mouth.

These four studies focus on ongoing customer relationships with both the vendor firm and the employee. Only two studies have addressed the impact of key contact employee turnover on customers' relationship with the firm. Beatty and colleagues (1996) report that retail customers, when asked hypothetically, stated that they would follow a store employee to a competing store if comparable products were available. Lovett, Harrison, and Virick (1997) draw on the resource dependence framework (Barney 1991) to present a conceptual framework of whether customer defection follows key contact employee turnover. Because the perceived dependence on a resource is greater when the resource is rare, valuable, inimitable, and nonsubstitutable, Lovett, Harrison, and Virick (1997) posit that customer defection is a function of the relative inimitability of the employee versus the firm. However, no research has empirically examined customers' concerns when a vendor firm's key contact employee leaves. Therefore, Study 1 explores the following two questions: What do customers value in their relationships with key contact employees? and What are customers' concerns about losing key contact employees?

\section{Methods}

Because our investigation is exploratory, our methods followed the guidelines for grounded theory development (Deshpandé 1983; Glaser and Strauss 1967). We collected data from business-to-business managers. Rather than rely on prior theories to test data in the traditional hypotheticodeductive approach (Keaveney 1995), we analyzed practitioner input from representatives of both vendor and customer firms, allowing patterns to emerge from the data. The sequence of research methods is detailed next.

Two researchers initially conducted a series of informal conversations with business-to-business managers: three vendors and seven buyers from seven companies. Five interviews were conducted in person and five by telephone. Both researchers participated in these conversations, which lasted between 30 and 45 minutes, and took extensive, independent notes during and immediately after the conversations took place. The researchers met and debriefed on the content of the conversations, aspects of business-to-business buyerseller relationships, and the vocabulary used by the respondents. An illustration of the refinement of our vocabulary is the use of the term "key contact employees" rather than "service providers." It quickly became apparent that though the marketing literature uses the term "service provider" to refer to an employee, business respondents use "service provider" to refer to the firm. An early respondent suggested the term "key contact employee," and when this term was used with subsequent respondents, it was more clearly understood and was adopted for the rest of the study.

On the basis of the insights developed through these conversations, we developed the moderator's guide for subsequent focus groups. We recruited focus group respondents using industry directories, personal contacts, and references. Because our primary interest is business-to-business relationships, we included services, industrial goods, and con- 
sumer packaged goods companies. We offered a copy of our findings as an incentive for participation. We conducted and moderated six focus group interviews. The size of the focus groups ranged from 10 to 15 subjects for a total of 72 respondents. The sessions lasted from an hour to an hour and a half. We formed the groups and conducted the interviews in accordance with accepted guidelines in the field (Calder 1977). Because homogeneity of the groups is regarded as an important facet to ensure open participation and because our respondents were business professionals, we emphasized homogeneity of rank and functional area rather than of sex or age. There were two groups of key contact employees ( 14 and 11 ), a group of 12 senior-level sales managers, a group of 10 human resources (HR) personnel, a group of 15 purchasing managers, and a group of 10 senior managers. Of the 72 participants, 44 were men and 28 were women. Participants' tenure with their firm varied: 10 had worked at the firm for 5 years or less, 20 for 6 to 10 years, 31 for 11 to 20 years, and 11 for 21 or more years.

\section{Data Analysis}

From audiotapes and detailed field notes available, six transcripts were prepared of the focus groups. Each researcher read the six transcripts individually and created lists of the aspects that customers valued in their relationships with employees (or aspects that employees and managers believed customers valued in their relationships) and of customers' concerns about losing favored key contact employees (or what employees and managers believed customers' concerns were). Through careful reading and rereading, researchers detailed passages and quotes that they believed reflected valued aspects of key contact employees or concerns about key contact employee turnover. The two researchers then met and compared their lists to identify areas of agreement and resolve any disagreements. Consensus was reached on all themes.

\section{Results: What Customers Value}

The focus group respondents believed that customers valued strong relationships with their key contact employees. For example, one respondent, a star sales representative for the pediatric products division of a major pharmaceutical firm, explained how he builds customer trust and loyalty by treating customers as individuals and providing special services. He remarked:

\begin{abstract}
You know, most pediatricians will remember their first rep from our company. I would meet them first when they were interns and give them free product if they had kids. When they are starting out, I helped them with educational materials for parents and talked to them honestly about our products and our competitors' products. What matters to one doctor may be different from what matters to the next.... You learn about them. It goes beyond just selling the product.... There was this specialist-a pediatric allergist-when she wanted to move, I called a couple of our reps in that area and asked if they knew any practices there that were looking for that specialty. It makes the reps there happy because if the doctor moves there, they are definitely going to have a chance to get their account, and if she doesn't move, she appreciates my help and will recommend me to others.
\end{abstract}

There was remarkable commonality across respondents when they discussed the employee characteristics that resulted in strong customer relationships. Some of the characteristics dealt with more objective performance measures such as expertise or industry experience, whereas others dealt with more subjective issues such as empathy or likability. This is consistent with marketing literature that makes a distinction between technical quality (what is delivered) and functional quality (how it is delivered) (Gronroos 1995). Similarly, in talking about how his employees develop strong rapport with the company's clients on the basis of the company's ability to customize the products, the president of an image management firm remarked,

Our account executives know the customer's business as well as he does. Only then can they really add value. [To customize, account executives] need to be able to anticipate customers' needs, don't wait for the customer to tell you what they need.

The president of a technology applications company suggested that competence was the key to building a strong customer relationship:

In projecting a positive image, there is no substitute for knowledge. An individual's answering "style" can certainly project a positive image during the first few seconds of a customer call, but without an underlying competence it doesn't go far enough.... Case studies abound with tales of motivated and empowered interdisciplinary team members that created customer loyalty resulting in the sale of gazillion widgets ... but there are just as many stories that are not reported about foul-ups and customer irritation caused by dealing with personable, well-meaning half-wits, who often know less than the caller about specifics! In my opinion, there is no substitute for good old-fashioned competence.

Key contact employee competence has ramifications beyond the practical application of knowledge. Many respondents alluded to customers' need to feel secure about entrusting their accounts to the key contact employee, and this is influenced by the customers' confidence in the key contact employee's expertise. According to the president of a networks technologies firm,

You should never undermine the authority of the employee in the customer's eyes. Even if the employee is getting significant help from more senior staff, the customer should see the employee as handling the big stuff.

Respondents also emphasized the role of subtler, interpersonal factors that make a key contact employee valuable to the customer. In speaking about her relationship with the manager of a support function, the director of an insurance company indicated that the reasons she valued him were numerous. The key contact employee was extremely competent, but she believed there was also value in the friendly relationship that had developed between them:

I would characterize our relationship as one of professional friendship. It has evolved naturally over time, and now we feel comfortable talking about his kids, our commutes, and so on. The fact that he is always pleasant and easy to like is a big part of why our professional relationship is so cordial.

\section{Results: Customer Concerns About Turnover}

After discussing what customers valued in their relationships with favored key contact employees, respondents 
talked about an actual situation in which a key contact employee was no longer available. As respondents discussed the situation, we explored what their concerns might have been, as well as their reactions. The director of field sales for a pharmaceutical firm spoke about his experience in observing customers in situations when they lost a key contact employee:

If your customer worked in the purchasing department of acute care hospitals, when their sales rep jumps ship and goes to a competitor, they may not immediately follow but they will at least give it a look. The reputation and the relationship the rep has built up get you to at least compare what your old rep's offering now. Before, you may say, why compare? Now, you look.

According to the ensuing focus group discussions, whether customers were concerned about key contact employee turnover in the vendor firm appeared to be a function of whether they believed that the key contact employee was a critical element of their satisfaction with the firm and, relatedly, whether they believed that the firm could assign an acceptable replacement to their account. Concerns were also affected by whether customers believed that the firm followed customer-friendly procedures in managing the turnover.

In terms of criticality, respondents brought up examples of situations in which it did not matter whether a key contact employee was no longer available. Respondents provided examples of strong relationships between the customer and the vendor firm that outweighed the relationships with the key contact employee. In discussing the relationships between a large bank's business customers and personal bankers, the bank's executive vice president remarked that the ties to the bank created a buffer that protected it from the turnover of key contact employees:

Our bank has been in the same location with the same name for 134 years. We have worked with many businesses from the ground up. We have several generations of businesspeople that have turned to us. That is not something our competitors can easily duplicate or that our customers can easily forget.

Focus group respondents indicated that employee turnover may also be offset by the firm's reputation for superior products. The following comment from a sales engineer at a leading consumer products firm who calls on large retailers illustrates this:

\footnotetext{
We are successful because of our ability to design and market innovative products. Our product development "engine" (designers, product engineers, CAD [computer-aided design] engineers, mold engineers, packaging engineers, prototype managers, product development managers, etc.) is synonymous with quality. Our customers view our company as an expert, whether the customer is Wal-Mart, Kmart, or Target. Customers don't like dealing with different reps from our side, but it's not that big a deal, given the reputation of the company.
}

Other respondents also mentioned less bottom-linedriven criteria, such as social conscience and image within the community, in assessing vendor firms. This is in keeping with recent conceptualizations of corporate associations along performance and institutional dimensions (Handelman and Arnold 1999). This idea was echoed by the president of a market research firm, who suggested that a firm's social image had much to do with retaining business clients:

\begin{abstract}
People think that the character of the company is less important in business-to-business relationships. But that is wrong. Businesspeople don't want to see themselves as robber barons! If they can, they will do business with a company that they know has a strong image and association with positive social values.
\end{abstract}

Other respondents discussed cases in which the customer's link with the key contact employee was a critical element in the customer's satisfaction with the firm. Respondents indicated that customers were very concerned about the acceptability of a replacement and the difficulty of replacing the key contact employee because of the special bonds that had been forged. The benefits director of an industrial goods manufacturer, in talking about a vendor's agent, provided an example:

The trustworthiness of the employees that deal with us is critical when vendors want to build strong relationships with us. We work with a vendor in our relocation area, where the customer service rep is very attached to us and vice versa.... We trust her to treat our employees the way we would treat them. We think of her as an extension of our company and that trust is what keeps us loyal to her. If we had to do business with someone else from the vendor's company, I would not be a happy camper. I couldn't be sure that whomever else they send would be able to work with us the same way.

Respondents also mentioned that "the employee must establish genuine familiarity with the customer and know that customer personally."

Another notion that emerged about the acceptability of a replacement employee pertained to time. Respondents indicated that when a customer resents losing a favored key contact employee, it is not necessarily because he or she believes a replacement will always be inferior to the key contact employee. Rather, the customer may be concerned about the time needed to bring the replacement employee up to speed. Consider the comments from the director of worklife strategies at a large insurance company about an internal supplier of data:

I have worked with him over the years, and we have gotten to the point where we work really well together. He always brings me the data when I need it. Great response time. And he sets it up exactly the way I want. He knows my history and customizes everything. If he leaves, someone else would take over, but it would take me a long time to get them to understand my needs and my priorities.

Respondents also mentioned the customer's level of confidence in being assigned an acceptable replacement. From the customer's perspective, there are two related sources of uncertainty: uncertainty about the quality of the replacement employee's performance (will he or she be as good as the previous key contact employee?) and uncertainty about getting the best replacement employee available to service the account. A partner in a major consulting firm talked about its efforts to reduce this uncertainty and build confidence among its clients: 
A client of ours is the CEO [chief executive officer] of a major pharmaceutical company. He says that one of the reasons he chooses us over our competitors is that with us, he can count on the consistency of the people we send him. He says to me, "I know you are always sending me new people, but it doesn't bother me because I always know they'll be great."

Respondents discussed the importance of the procedures used to inform customers of employee transitions and to ensure that customer service levels will be maintained. Several respondents indicated that when employees were transferred, promoted, or left the firm, the customers were always the last to know. Procedures to inform customers of impending changes and how they would be handled were viewed as being extremely valuable but also rarely used.

\section{Discussion and Research Propositions}

The focus groups confirmed the existence of strong relationships between key contact employees and customers in business-to-business relationships. Respondents indicated that customers valued key contact employees to the extent that they were able to customize the product, were competent, inspired a sense of security, and fostered personal friendships with the customers. It was also evident from the focus groups that customers were concerned about losing favored key contact employees when the employee relationship was critical to the customer's satisfaction with the firm. The concerns centered on the acceptability of a replacement employee-that is, the potential performance gap between the key contact employee and a replacement employee-and on the procedures used in the transition.

The insights developed from the focus groups lead to the following propositions regarding customers' reactions when faced with key contact employee turnover:

$P_{1}$ : In the event of key contact employee turnover in a vendor firm, the vulnerability of the vendor firm's relationship with the customer will be inversely related to the customer's perception of how critical the key contact employee relationship is to the customer's satisfaction with the vendor firm.

$P_{2}$ : In the event of key contact employee turnover in a vendor firm, the vulnerability of the vendor firm's relationship with the customer will be inversely related to the customer's confidence that an acceptable replacement employee will be available.

$\mathrm{P}_{3}$ : In the event of key contact employee turnover in a vendor firm, the vulnerability of the vendor firm's relationship with the customer will be directly related to the amount of time the customer believes it will take the replacement employee to match the service level of the former key contact employee.

$P_{4}$ : In the event of key contact employee turnover in a vendor firm, the vulnerability of the vendor firm's relationship with the customer will be inversely related to the customer's perception of the replacement employee's knowledge of the product, the industry, and the customer's specific situation.

$P_{5}$ : In the event of key contact employee turnover in a vendor firm, the vulnerability of the vendor firm's relationship with the customer will be inversely related to the customer's confidence in the consistency of the quality and performance of the vendor firm's employees.
$P_{6}$ : In the event of key contact employee turnover in a vendor firm, the vulnerability of the vendor firm's relationship with the customer will be inversely related to the customer's confidence in the trustworthiness of the vendor firm's employees.

$\mathbf{P}_{7}$ : In the event of key contact employee turnover in a vendor firm, the vulnerability of the vendor firm's relationship with the customer will be inversely related to the customer's confidence in the friendliness of the vendor firm's employees.

$P_{8}$ : In the event of key contact employee turnover in a vendor firm, the vulnerability of the vendor firm's relationship with the customer will be inversely related to the customer's satisfaction with the procedures used by the vendor firm in the notification and management of the transition.

\section{Study 2: Managing Key Contact Employee Turnover: Background and Methods}

\section{Conceptual Background and Research Questions}

The focus group discussions in Study 1 demonstrated that, in several situations, customers were concerned about losing favored key contact employees and, with them, the knowledge and rapport that had been established. It also became clear that customers, key contact employees, and managers believed that key contact employees were valuable repositories of knowledge about the customers. This suggested that vendor firms must simultaneously address customers' concerns about key contact employee turnover and fashion strategies to retain key contact employee knowledge.

Our careful review of the marketing and management literature revealed that there is no published work that directly addresses what vendor firms can do to alleviate customer concerns. There is a considerable body of literature on information sharing, but it does not address employees sharing information with the firm.

The information that an individual key contact employee possesses may be classified as declarative or procedural. Declarative knowledge is more content-based and deals with facts, events, or propositions (Anderson 1983; Cohen 1991), whereas procedural knowledge deals with "how things are done" (Cohen and Bacdayan 1994). Although these constructs originated in individual-level knowledge, scholars have begun applying them to the study of firms (e.g., Moorman and Miner 1997, 1998). Relevant research in marketing regarding information sharing has studied how organizational knowledge may affect product innovation (Lukas and Ferrell 2000; Moorman and Miner 1998), the links to market orientation (Baker and Sinkula 1999), and the factors that make it likely that the recipient of information will trust or act on it (e.g., Moorman, Zaltman, and Deshpandé 1992). Similarly, much research exists in the management arena that deals with how to create a learning organization (Easterby-Smith 1997; Senge 1990), in which information from employees is collected and analyzed by the firm.

The focus of our study is quite different. By examining when employees are most likely to share information with the firm, we investigate what makes for a "teaching organization," in which knowledge collected and held by the firm is disseminated to its employees. The literature that corre- 
sponds to this question relies on examining what firms can do so that employees will perform to set expectations. In an article that deals with performance gaps, Chenet, Tynan, and Money (1999) suggest that employees' compliance with company standards is influenced by several factors, such as trust, cooperation, and shared values. However, Chenet, Tynan, and Money's (1999) article focuses on general compliance with standards, not on capturing employee knowledge. The article is conceptual, and no empirical data are provided in support of the proposed model or implied effects. Therefore, Study 2 is designed to address the gaps in current literature by examining the following two questions regarding key contact employee turnover:

1. What can vendor firms do to alleviate customers' concerns about turnover?

2. What can vendor firms do to retain the knowledge their employees possess?

\section{Methods}

Because of the scarcity of literature addressing these questions, we continued the grounded theory approach of Study
1 , relying on practitioner input to generate insights and further theory building. We secured practitioner input through depth interviews and surveys. Figure 1 shows the sequence of research methods, which we discuss next.

Depth interviews. We used a purposive sampling plan to provide broad representation. We contacted 60 managers from 16 companies throughout the world to schedule depth interviews. We described the focus of the study, asked for an hour's time for an interview, and offered a copy of the research findings as an incentive for participation. Of this group, 47 managers agreed to participate, for a response rate of $78 \%$. Each of the 16 companies was represented in the final sample. Interviews lasted between 30 and 60 minutes. We made every attempt to conduct the interviews in person, but because of the large geographic dispersion of the respondents, we conducted 22 of the in-depth interviews over the telephone. We believed that telephone interviews were necessary to obtain the diversity of companies, geographic areas, and levels of management we wanted for this study.

The sample included participants from both vendor companies and customers. Respondents included employees from marketing, purchasing, operations, and information

\section{FIGURE 1}

\section{Sequence of Research Methods for Study 2}

Purpose: To understand vendor firm strategies to alleviate customer concerns about key contact employee turnover and to capture key contact employee knowledge.

\begin{tabular}{ll} 
Sample: & \multicolumn{1}{c}{ Depth Interviews } \\
\cline { 2 - 2 } & 60 managers from 16 companies \\
contacted. 47 managers participated. \\
All companies represented.
\end{tabular}

Data collection:
25 interviews conducted in person, 22 interviews by telephone. Interviews lasted 30-60 minutes.

\section{Surveys}

100 managers from 34 companies contacted. 83 managers participated. All companies represented.

E-mail and hard copies mailed to managers. Open-ended questions.

Data analysis: Transcribed interviews and surveys analyzed as described below.

Step 1: Independent text analysis of interview transcripts and surveys by Judges A and B. Each judge identified discrete behaviors mentioned in the text. Comparison of lists yielded interjudge reliability of .92, exceeding the preestablished .8 cutoff.<smiles>[3H][13CH3]</smiles>

Step 2: Judges A and B independently developed a list of themes to capture the discrete behaviors identified in Step 1. The judges exchanged lists, reviewed the themes identified, and jointly created a master list of themes. Interview transcripts and surveys were jointly coded by Judges $A$ and $B$ for mention of themes by each respondent to develop a benchmark classification.<smiles>C[12CH]</smiles>

Step 3: Independent Judges $C$ and D were given the list of themes generated from Step 2, along with copies of interview transcripts and surveys. Judges $C$ and $D$ independently coded the mention of themes by each respondent. These judges identified no new themes. Interjudge reliability compared with the benchmark comparison (Judges $A$ and $B$ ) was .88 for Judge $C$ and .92 for Judge $D$, exceeding the preestablished .8 cutoff.

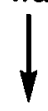

Step 4: Independent Judge $E$ was given the list of themes generated from Step 2 and copies of the interview transcripts and surveys. Judge $E$ coded the mention of themes by each respondent. No new themes were identified by Judge $E$. Interjudge reliability compared with the benchmark comparison (Judges A and B) was .92, exceeding the preestablished .8 cutoff. 
technology and HR managers. These managers came from various levels within their companies, which ranged from Fortune-100 to small and medium-size companies. The respondents were 7 senior managers (presidents, CEOs, and executive vice presidents of functional areas), 9 senior marketing managers, 11 purchasing managers, 4 managers from operations, 1 manager from information technologies, $6 \mathrm{HR}$ managers, and 9 sales representatives. Of the 47 participants, 33 were men and 14 were women. Respondents' tenures with their company varied: 8 people had been with the company for 5 years or fewer, 12 between 6 and 10 years, 17 between 11 and 20 years, and 10 for 21 or more years.

The depth interview is a well-established method for collecting data (Peñaloza 2000; Thompson 1997), especially with executives (Kohli and Jaworski 1990; Workman, Homburg, and Gruner 1998). We developed depth interview guidelines in line with recommendations by McCracken (1988) and Thompson, Locander, and Pollio (1989). Respondents were told the purpose of the study, and confidentiality was assured. We began with a "grand tour" question (Ruth, Otnes, and Brunel 1999) to focus on the domain of the study and asked for a description of a case in which a favored key contact employee was no longer available to serve a customer. After the grand tour question, respondents were asked a series of probing questions to encourage them to provide more detailed information. Customers were asked about their responses to key contact employee turnover and the actions that were or could have been taken by the vendor firm. Key contact employees were asked about the actions taken by their firm in managing customer relationships, their insights into customers' perspectives, and their firms' efforts to retain their knowledge. Vendor firm managers from various functional areas were asked similar questions and for their insights about retaining key contact employee knowledge.

Building on this broad response base enabled us to develop a comprehensive perspective of customers' perceptions about losing key contact employees and firm strategies that might affect those perceptions. We avoided questions that asked respondents to explain why they did things in a particular way so that respondents would not feel compelled to justify their actions. This was important in conversing with executives, who may be sensitive about defending their business decisions. Instead, our focus was to obtain answers to descriptive questions that sought information on strategies that were in place to handle key contact employee turnover. We used questions and probes to generate exemplars and obtain clarification rather than to confirm or disconfirm any set hypotheses. When the respondent had insights that we believed were valuable in developing a richer understanding of the problem and/or when a respondent had specific case examples, we probed deeper.

Surveys. Although depth interviews are a valuable research tool, scheduling issues and the required time commitment discourage participation from a broad base of managers. Consequently, to complement the depth interviews, we administered a brief, open-ended questionnaire to a different sample of respondents. We adopted a purposive sampling method and sent both an e-mail version and a hard copy of the questionnaire to 100 executives from different functional areas in 34 diverse companies and geographic regions. The cover letter explained the purpose of the study and assured respondent confidentiality. Respondents were encouraged to write in examples, illustrations, or comments for all questions, and they could send the completed surveys by regular mail, e-mail, or fax. As an incentive for participation, respondents could request a copy of the research findings.

Depending on the respondent's position, he or she was sent one of three versions of a questionnaire. The format and questions were identical to the depth interview, starting with a grand tour question that asked for a description of a situation in which a key contact employee was no longer available. This was followed by questions specific to the respondent's status as a customer, key contact employee, or manager of a functional area. Of the 100 managers contacted, 83 complied, and all 34 companies were represented. Respondents were 15 senior managers (president, CEO, executive vice president of functional area), 11 marketing managers, 15 purchasing managers, 3 managers from operations and logistics, 13 HR managers, 3 managers from management information systems, 3 managers from research and development, and 20 sales representatives. Of the 83 respondents, 51 were men and 32 were women. Respondents' tenures with their company varied as follows: 26 people had been with the company for 5 years or fewer, 25 between 6 and 10 years, 24 between 11 and 20 years, and 8 for 21 or more years.

\section{Data Analysis}

To draw insights from the depth interviews and survey responses, we followed a strict protocol for interpretation that proceeded in a series of part-to-whole iterations (Thompson, Pollio, and Locander 1994). Consistent with prior research (Keaveney 1995), we determined that using discrete behaviors in a transcript would be a better unit of analysis than coding the transcript as a whole. The following describes the steps in data analysis, as shown in Figure 1.

Step 1: Identifying behaviors. Two of the researchers involved with the project, Judges A and B, each read all of the 47 interview transcripts and 83 surveys to identify specific discrete behaviors, defined as distinct actions. For example, when a respondent talked about his firm not letting a key contact employee work with an account for longer than two years and about featuring employees in firm newsletters, these were coded as two discrete behaviors. After the specific, discrete behaviors were identified, the two researchers met to compare lists. The interjudge reliability was .92 , exceeding the .8 cutoff in prior literature (Keaveney 1995). Points of disagreement were resolved through discussion, and a consensus was reached on all items. A total of 556 discrete behaviors were identified, an average of 4.3 behaviors per respondent.

Step 2: Developing themes for benchmark classification. To generate common themes that incorporated several behaviors, Judges $\mathrm{A}$ and $\mathrm{B}$ prepared an individual analysis of the ideas presented in the interviews and surveys. The judges developed themes for addressing customer concerns 
using the input of customers, key contact employees, and managers. They developed themes for retaining key contact employee knowledge using input from key contact employees and managers. The researchers exchanged drafts of the themes, compared their lists, and engaged in a joint analysis whereby they read and reread behaviors to achieve consensus on the themes identified across respondents. On completion of this task, 15 themes were identified, 10 dealing with addressing customer concerns about key contact employee turnover and 5 dealing with retaining key contact employee knowledge.

Judges A and B then reviewed each transcript and survey together to note whether a respondent mentioned any of the themes. If a respondent gave two examples of the same theme, the judges would mark only that the respondent mentioned that theme, not that it was mentioned twice. For example, if a respondent mentioned that his or her firm featured employees in firm newsletters and in annual reports, the judges would mark that the respondent mentioned the theme "showcasing employees." By classifying respondents together, the judges were able to resolve any points of disagreement. Consensus was reached, and these results became the benchmark for comparison.

Step 3: Reliability check of benchmark classification. Two judges, $\mathrm{C}$ and $\mathrm{D}$, who were not previously involved with the research project, were recruited as coders. Judges $C$ and $\mathrm{D}$ were given a set of all transcripts and surveys, along with the list of themes developed in Step 2. They were instructed to read each transcript and survey carefully and note whether a respondent made any mention of each theme. Any time the judges noted that a theme was mentioned, they were asked to note which specific behaviors they used as indicators of that theme. The coders also were instructed to create new themes if they believed it was necessary and list the specific behaviors they would categorize under that theme. No new themes were identified. The interjudge reliability relative to the benchmark exceeded the .8 cutoff, with values of .88 for $C$ and .92 for $D$, for an average of .90 .

Step 4: Additional verification. As a further check for whether the counts of themes were "intersubjectively unambiguous" (Hunt 1983; Keaveney 1995), as measured by interjudge reliability, a fifth judge, E, previously unrelated to the research project, was given the set of surveys and transcripts along with the list of themes. As in Step 3, Judge $E$ read all the transcripts and surveys in their entirety and noted whether each respondent made any mention of each theme. Judge $E$ also was asked to identify any new themes if necessary, along with behaviors categorized under that theme. No new themes were identified. The interjudge reliability between this judge and the benchmark consensus of Judges $A$ and $B$, computed as the percentage of agreement, exceeded .8 , with a value of .92 . The list of themes and the number of mentions of each theme across the respondents, identified by Judges $A$ and $B$, are given in Table 1. For presentation purposes, the themes were categorized by Judges A and B into three higher-order groupings based on the focus groups, which are shown in Table 1.

TABLE 1

Frequency of Mention of Themes by Depth Interview and Survey Respondents

Strategies to Address Customer Concerns About Losing a Key Contact Employee ( $\mathrm{n}=130$ respondents)

\begin{tabular}{|c|c|c|}
\hline \multirow[b]{2}{*}{ Perceived criticality } & Themes & Frequency \\
\hline & $\begin{array}{c}\text { Rotation } \\
\text { Teams } \\
\text { Multiple contacts } \\
\text { Vendor firm image }\end{array}$ & $\begin{array}{l}12(9 \%) \\
23(18 \%) \\
48(37 \%) \\
46(35 \%)\end{array}$ \\
\hline Acceptability of replacement employees & $\begin{array}{c}\text { Selection and hiring } \\
\text { Training } \\
\text { Showcasing employees } \\
\text { Tangible cues }\end{array}$ & $\begin{array}{l}22(17 \%) \\
65(50 \%) \\
24(18 \%) \\
13(10 \%)\end{array}$ \\
\hline Procedures in transition & $\begin{array}{l}\text { Advance notification } \\
\text { Planned transition period }\end{array}$ & $\begin{array}{l}12(9 \%) \\
14(11 \%)\end{array}$ \\
\hline \multicolumn{3}{|c|}{ Strategies to Retain Key Contact Employee Knowledge ( $n=104$ respondents) } \\
\hline & Themes & Frequency \\
\hline Valuing employee information & Culture of sharing & $59(57 \%)$ \\
\hline Employee motivation & $\begin{array}{c}\text { Performance appraisal and reward systems } \\
\text { Trust and commitment }\end{array}$ & $\begin{array}{l}40(38 \%) \\
25(24 \%)\end{array}$ \\
\hline Employee ability & $\begin{array}{c}\text { Technology } \\
\text { Organizational structure }\end{array}$ & $\begin{array}{l}40(38 \%) \\
13(13 \%)\end{array}$ \\
\hline
\end{tabular}




\section{Results for Research Question 1: Strategies to Address Customer Concerns}

Consistent with the focus groups, the depth interviews and survey responses suggested that customers are quite sensitive to the loss of a key contact employee. Consider the statement of a buyer at a major automotive manufacturer:

\begin{abstract}
During my last rotation at as a buyer of braking systems, the sales representative for my primary supplier ... moved to a new position. This person had been in his job for several years and was well respected by both the buyers and the engineers in our company. He was replaced by someone who is also a competent sales rep and had several years of experience but had not developed the same kind of relationships with our personnel. In addition, this company was going to be involved with several critical sourcing decisions in the weeks following this job change. I was very concerned that the sourcing process might be affected by switching the sales rep as these sourcing decisions were being made.
\end{abstract}

The ten themes that emerged from the interviews and surveys pertaining to customer concerns about key contact employee turnover are presented under three headings: criticality of key contact employees, acceptability of replacement, and procedures used in the transition.

\section{The Criticality of Key Contact Employees}

The situations that made the loss of the employee less critical to the customer's satisfaction with the vendor firm all dealt with factors that created mitigating circumstances to lessen the impact of a replacement employee. These included (1) rotation, (2) teams, (3) multiple contacts, and (4) vendor firm image.

Rotation. Rotating the key contact employees was a strategy mentioned for lessening the impact of losing any specific key contact employee. A senior manager of a major industrial products manufacturer had this to say about rotation:

\begin{abstract}
We try to make sure that several of our reps interact with our major customers. You don't want the entire relationship destroyed because the customer depends on just one person. Many companies ... use rotation and change the contact people by design.
\end{abstract}

This practice results in the customer being exposed to several employees who can fulfill the key contact function. Respondents in consulting, advertising, and technology systems were quick to point out that they typically presented their use of rotating key contact employees as a strategy to bring fresh, unbiased perspectives to customers. Furthermore, the information about the customer resides with several employees instead of with a single key contact employee (Lahti and Beyerlein 2000). This can minimize the importance of the key contact employee, because no individual dominates the customer relationship over a long period of time.

However, from the customer's perspective, this did not always seem to be a welcome strategy. According to the purchasing manager for a large industrial goods manufacturer,
I always prefer having to do business with the same person. It is easier that way. You don't have to rehash the whole story. You don't have to worry about how much they know about your company, the product they're selling. You develop a real relationship over time. You get to the point where you can almost read each other's mind without saying anything. It's hard to deal with different people every so often and have that kind of understanding.

There also may be benefits of rotation to the customer, as the following comment from a purchasing manager illustrates:

Through rotations, I went through four sales representatives at one of my main suppliers. From the standpoint of maintaining a constant stream of information, that made my job a lot tougher... Actually having to "teach" my suppler representative about his/her product line was an interesting twist.... I was able to teach the supplier representative what I wanted him to learn. This was great because it gave me a lot of negotiation leverage. In many instances, my "adversary" was actually my ally.

Teams. Both vendor firm and customer respondents mentioned teams as reducing the impact of losing key contact employees. Various team structures were described. Some respondents talked about how companies used crossfunctional teams to sell and service customers, and others mentioned the pairing of junior and senior salespeople or the pairing of a field salesperson with someone from customer service. A senior bank executive talked about his firm's efforts to build relationships between its business customers and the outside and inside salespeople who work as a team to serve them:

The outside and inside salespeople work as a close-knit team in serving the customer. The outside salesperson may only see the customer once every couple of weeks, but the inside salesperson may talk to them many times, even in a single day. Even if one of them leaves, the team knowledge about the customer is still there.

Companies can use cross-functional teams to sell or to service customers. Such teams ensure that the customer's bonds are spread across team members rather than focused on one individual. Even if the customer believes a replacement employee would not be as good as the current employee (e.g., the customer believes the firm's best sales engineer is on the team), the gap becomes less important given the customer's multiple relationships with team members. The senior purchasing officer of a major automobile manufacturer talked about his experience with the team approach adopted by a vendor:

Our primary battery supplier always has two people working with us-one senior person who manages the account and a more junior person who comes along on all the visits. On one occasion, we were trying to make an important decision and the senior rep was not available because he had an appendectomy. It really made it easier because we already knew the junior person on the team.

Multiple contacts. Another practice mentioned by respondents was the cultivation of multiple contacts with a customer's business. Whereas teams focus on serving one aspect of a customer's business at a point in time, multiple 
contacts are used to address different aspects of the customer's business. The president of a company that manufactures cameras for scientific applications indicated that he relied on providing multiple contacts to insulate his business from the effects of an individual employee needing to be replaced.

\begin{abstract}
We engage with the customer on many different levels ... for example, a salesperson, engineer, and production/ scheduling person (each a specialist in their field) could engage with the customer to help out at different stages. This is relatively easy to do with the help of e-mail, conference calls, etc. Often, it is enough to give a customer (or a prospective customer) the contact information for all the potential support people that may be available to solve a particular set of issues.
\end{abstract}

Providing a chain of contact points can complement the use of rotation and teams by making different people or units responsible for different functions for the customer (e.g., one person to contact for after-sales service, a separate person or unit for billing). Providing multiple contacts can also help a firm create a one-stop shop for multiple services (Zinn and Parasuraman 1997), as the following quotation from a customer illustrates:

\begin{abstract}
Since we are building a car, our suppliers who are able to provide several components are a lot easier to work with since they can share information across groups and serve us better. When I go to my guy - even if he might not completely understand the system, I am confident he has access to the information from someone else in his company. This saves me time and helps them deliver a high level of service.
\end{abstract}

An additional way to create multiple contact points, according to the respondents' input, was to highlight the role of social interactions between the customer and several employees who work on the customer's account at various levels. An executive we interviewed talked about the impact these programs had on him as a customer:

When I go to picnics and barbecues that this vendor holds, I see all the people that are working on my account to keep my business. I even get to see back-office employees that I wouldn't normally deal with. This makes me realize that the company has a lot of employees that really value me as a customer and can service my account.

The more points of contact there are between the customer and the firm, the less critical any single employee relationship seems to be. However, even in the presence of multiple contacts, some respondents expressed a preference for a single key contact employee to serve their account because they wanted to know that someone was always in charge and responsible for the account. A purchasing manager at a Fortune-500 company had this to say:

Because the companies we buy from often make more than just one product, there are other people from within my organization that buy from that supplier too. Many times, suppliers will introduce their buyers to many different people. This can be very confusing, and it is easy for the supplier to pass the buck. That is why I always want to make sure that I understand the sales organization that I interface with. I want to know that I am working with one person that is high enough in the organization to make key decisions about sourcing and pricing.
Vendor firm image. Respondents mentioned that a positive vendor firm image affects the criticality of a key contact employee to customers. This image may be cultivated through tangible cues (uniforms, business cards, stationery, and so on), promotional strategies, patents and other proprietary assets, or corporate citizenship (Maignan, Ferrell, and Hult 1999).

A firm's use of effective tangible cues appears to go beyond the employee to every aspect of the firm that is visible to the customer. A director of marketing for a national chemical products company talked about his firm's difficult decision to outsource the trucking division:

At our company, the clean, polished, well-kept trucks were a point of pride and viewed as a reflection of our company's attention to detail. Outsourcing this function was considered very carefully in terms of the potential loss in customer goodwill and recognition of our company's name and our image. We needed to be sure the company we selected to outsource would maintain the same standards.

In talking about strategies to build firm image, respondents mentioned the use of corporate advertising to emphasize their leadership in the marketplace. The president of a major advertising agency discussed his firm's tactic of advertising that among the agency's clients are the producers of five of the top seven global brands. The senior purchasing officer in an industrial goods manufacturer included such considerations in making purchases:

I worked in the corporate purchase office and was dealing with two furniture companies. I knew this one company has donated money to charity, helps in the community a great deal, so I gave that company the first shot at our business. The other company, I'd never heard about anything they'd done like that. Citizenship, giving back to the community, that mirrors our corporate values, and if I can do business with suppliers like that, great.... I wouldn't have gone with them if they had a lousy rep, bad service, or if I had to pay a premium to work with them... Still, other things equal, there's no doubt that's where the business would go.

Prior research also shows that the image of a firm is affected by corporate citizenship, which may affect customer responses (Barone, Miyazaki, and Taylor 2000).

Propositions. The input from practitioners leads to the following propositions regarding criticality:

$P_{9}$ : In the event of key contact employee turnover in a vendor firm, the impact of the loss of the key contact employee on the customer's satisfaction with the vendor firm is inversely related to the vendor firm's use of rotation of key contact employees.

$\mathbf{P}_{10}$ : In the event of key contact employee turnover in a vendor firm, the impact of the loss of the key contact employee on the customer's satisfaction with the vendor firm is inversely related to the vendor firm's use of teams of employees to serve customers.

$P_{11}$ : In the event of key contact employee turnover in a vendor firm, the impact of the loss of the key contact employee on the customer's satisfaction with the vendor firm is inversely related to the vendor firm's use of multiple contact points with different areas of a customer's business.

$P_{12}$ : In the event of key contact employee turnover in a vendor firm, the impact of the loss of the key contact employee on 
the customer's satisfaction with the vendor firm is inversely related to the vendor firm's positive image.

These propositions are consistent with marketing theory that the strength of the relationship with the firm is an important determinant of customer evaluation in the business-to-business setting (Leuthesser 1997; Weitz and Jap 1995). A strong relationship with the firm appears to offset key contact employee turnover in the customer's mind, acting as a buffer against negative responses. Some caveats are in order with regard to the propositions on rotation, teams, and multiple contacts. Although rotation may help familiarize the customer with several key contact employees, customers may resent needing to create new relationships. It also may have the unfortunate consequence of preventing the customer from developing a strong relationship with any employee. With respect to teams and multiple contacts, some respondents mentioned that they felt overwhelmed by having to deal with multiple people from the vendor's side.

\section{The Acceptability of Replacement Employees}

The acceptability of a replacement employee emerged as a major concern in both the focus group interviews and the subsequent depth interviews and surveys. Managers in the depth interviews and surveys stated that several avenues were open to vendor firms to improve the perception of potential replacement employees. Four themes captured the specific examples furnished by the managers: (1) selection and hiring, (2) training, (3) showcasing employees, and (4) tangible cues. We discuss these strategies next.

Selection and hiring. Respondents indicated that the selection and hiring practices of vendor firms affected customers' perceptions about the quality of replacement employees. The following is an illustrative response from a senior purchasing officer at a large chemical company:

\footnotetext{
The quality of the people they send you is quite critical. If I am buying material and equipment, and if it's not right, it can shut the plant down, cost us a shift, millions of dollars, then I want to know what kind of people make it through at the vendor's company, and I'll even ask them, what are you guys doing? Who else are you adding to the team this year? If I'm buying paper clips from them, I wouldn't care who they hired. I mean, the worst thing is, hey, we're out of paper clips for a day or two. But if the people who sell me these OEM [original equipment manufacturer] systems don't know what they're talking about, my butt's on the line.
}

Firms often showcase their reputation for being highly selective employers or desirable places to work. With respect to selection and hiring practices, the director of training for a major industrial manufacturer said,

\begin{abstract}
When our company was selected as a great place to work, it was a critical selling point with customers. Our company made a video of the workplace and placed excerpts on salespersons' computers. Salespeople are encouraged to share snippets with customers. When our salespeople do this, it makes the customers more confident about the company and the type of salespeople we can hire.
\end{abstract}

Selection and hiring may enhance the image of all employees (Pfeffer, Hatano, and Santalainen 1995). Cus- tomers may reason that a vendor firm with stringent standards would hire only the best candidates, and therefore any key contact employee would be viewed more positively than one who works for a firm with less rigorous standards. A firm also may play up its ranking as an employer of choice. Placements in "best places to work" lists or similar rankings may signal that there is a great deal of demand for jobs in the firm and that, therefore, the firm can afford to be selective (Hannon and Milkovich 1996).

Training. The importance of training was another common theme when respondents discussed how vendor firms could improve the perceived quality of replacement employees. The director of customer service at a major pharmaceutical company strongly believed that this was an important aspect of the employees' image with customers:

\section{We put all of our employees through rigorous training. Not just sales techniques, but we teach them about all of our products and our competitors' products. This requires us to teach courses on human physiology, diet, prescriptions, and even toxicology. We let our customers know that when they talk to our reps, they are talking to people with a col- lege degree and many hours of intensive training.}

Frequently, vendor firms advertise the rigorousness of the training provided to employees as a way of increasing customers' confidence in the quality of the employees in the firm and the service they provide (Brown 1998). The effects of these training perceptions can be considerable. According to the senior manager of purchasing responsible for carrier contracts at a major industrial goods manufacturer,

I pay attention to how these vendors train their people. We do a lot of business with truckers, and they talk a lot about the selection criteria they use for their drivers, the training they provide, not just one-time but ongoing safety training programs. That kind of thing is very big. If we can't be sure about their training, I just can't take that kind of risk. In some kind of chemicals we buy, the purity of it is very important. We use it to process semiconductor chips. Then, again, the training the vendor gives their product and quality assurance folks is critical to us. This supplier I have dealt with over the years does a fantastic job of training all their people and always lets us know of new programs they have, and it really reassures me and keeps me doing business with them.

Showcasing employees. Respondents also spoke about vendor firms showcasing their employees to customers as a way to influence positive perceptions of all employees and increase the acceptability of replacement employees. Several senior managers mentioned that their companies made concerted efforts to showcase their employees by trying to get all personnel promotions, appointments, and awards in the press. Respondents believed that all this visibility enhances the client's perception of the quality of the personnel. Such efforts both pave the way for employees to build new relationships with customers and reassure existing customers of the value of these employee relationships (Howard 1998). The people we interviewed mentioned the prominent role that employees were given in their advertising and annual reports, emphasizing their caring, trustworthiness, competence, and professionalism. As one respondent commented, 
There's this one supplier that has a great reputation with our people. When one of their design team folks wins an award, or they are recognized in their industry as best in class, we know about it the very next day. In this business, it is all about the quality of the company and their reliability, and when their people are singled out like that, that recognition really catches your eyes.

Tangible cues. Respondents mentioned also that vendor firms encourage their employees to use tangible cues such as dress, business cards, and class of travel to elevate their image. A senior partner within the business products division of a major consulting firm stressed the role of tangible cues in conveying the desired employee image. He stressed that his firm held orientation sessions for new employees to inform people how important it was for all employees to convey a consistent, high-quality image.

We tell our employees to always dress in a businessappropriate fashion, even when they are traveling on assignment. You never know who might be sitting next to you, and we want any potential customer to get the right idea about our company by looking at any one of our employees.

From the customer's perspective, the tangible cues seem to provide some sense of quality. The comments of a purchasing manager for a supplier of specialty chemicals spoke about this aspect:

I think I'm like the majority of people. If you call on me in Dockers with ratty bottoms or crappy shoes, looking unshaven, unclean, I don't want to do business with you, no matter how smart you are. But sometimes, when a person shows up in a suit or a tie, it's like they're trying to look better than you. We tell suppliers we're a business casual workplace. Sometimes though, it's funny. We have suppliers from overseas or from the East Coast and they still seem to dress more formal. But they kind of apologize. They tell us, "hey, I've got to call on three other accounts after this and they're not real casual."

It was clear from the examples respondents mentioned, such as employees' uniforms and accessories, that these tangible cues may be considered part of the "packaging of the employee" (Solomon 1985). Vendor firms must be conscious of integrating the messages conveyed by every element of the tangibles associated with employees, from their appearance and dress to their identification tags or business cards. Bitner (1990) shows that such physical cues can have a significant impact on the interpretations customers make about various employee actions.

Propositions. We offer the following propositions to summarize the insights on the acceptability of a vendor firm's replacement employee:

$P_{13}$ : In the event of key contact employee turnover in a vendor firm, from the customer's perspective, the acceptability of a replacement employee is directly related to the vendor firm's reputation for selective hiring of employees.

$\mathbf{P}_{14}$ : In the event of key contact employee turnover in a vendor firm, from the customer's perspective, the acceptability of a replacement employee is directly related to the vendor firm's reputation for training employees.

$P_{15}$ : In the event of key contact employee turnover in a vendor firm, from the customer's perspective, the acceptability of a replacement employee is directly related to the vendor firm's practice of showcasing its employees.

$P_{16}$ : In the event of key contact employee turnover in a vendor firm, from the customer's perspective, the acceptability of a replacement employee is directly related to the quality of the tangible cues provided by the vendor firm's employees.

It appears that vendor firms may benefit by creating positive perceptions about the overall quality of their employees. As the quality of the employees increases, there is a greater likelihood that a customer will receive a high-quality replacement if his or her particular key contact employee were to leave. The customer still may believe that his or her key contact employee is superior, but as the absolute level of quality of the replacement employees rises, any difference between the key contact employee and the replacement will be less important.

\section{Procedures Used in the Transition to the Replacement Employee}

The depth interviews and surveys reaffirmed how the procedures used by the vendor firm affect how customers respond to the loss of a key contact employee. A review of the transcripts indicated that a vendor firm should keep customers abreast of any personnel changes through (1) advance notification and (2) a planned transition period.

Advance notification. Many respondents indicated that advance notification of the change by the vendor firm reassures customers. According to a purchasing manager,

It would have been helpful to have the company do something in advance of the transition. They could have provided me with a written notice of the change. They could have given me written or verbal indication as to the readiness of the new person and that person's qualifications.

The marketing manager at a large insurance company presented a way to provide advance notification that he thought would work for key contact employees in his organization.

One thing I would like to do is set up a system so that when our business customers have to deal with a new rep, they get a letter from the old rep that says, "Thank you. I have enjoyed working with you. Now, let me introduce my replacement. They will serve you just as well." Of course, this is easier to do when the old rep has been promoted in our company. But we don't do that. We have turnover, and promotions, and many organizational changes, and nothing goes out to the customers. We send something after but that seems like too little, too late.

A planned transition period. Customers are concerned that a replacement employee may not understand the parameters of their business or that they may not have the same relationship they enjoyed with their old key contact employee. A planned transition period between key contact employees emerged as a critical variable in the successful management of the vendor firm-customer relationship. A buyer for a major auto manufacturer provided the customer's perspective on the management of transitions: 
When I lost my sales rep, nothing much was done to address my concerns. There was a brief transition period when the outgoing sales representative, the new one, and I met to discuss open issues and upcoming events. It would have been so helpful to have a longer transition period, where the new sales representative could get up to speed and begin developing relationships with our personnel without the pressures of completing the day-to-day work associated with the position.

Respondents mentioned that such transitions would make it easier for the customer and the new sales representative to share critical information. Suggested transition efforts included having the old employee introduce the new replacement, act as a bridge for the initial transition period, and reassure the customer about the handoff.

However, there was awareness that such transition is not always possible between the old employee and the replacement, especially when the old employee is hired away by a competitor and leaves abruptly, rather than is promoted or moved within the firm. Suggestions were offered to address this scenario as well. According to a purchasing manager,

Companies should provide a transition period-that would be very apparent-where new and old reps attended meetings together, made calls together, etc. This could perhaps occur over a 2-4 week period. In the event the old employee leaves, and there is no time to do this, the sales manager should have taken charge of the account, jointly attended meetings and so on, until the replacement and the buyer are comfortable. This would tell me that they value my business.

Propositions. The following propositions are offered regarding the procedures used in transitions:

$P_{17}$ In the event of key contact employee turnover in a vendor firm, from the customer's perspective, satisfaction with the procedures used in the transition to the replacement employee will be directly related to the vendor firm providing advance notification of the transition.

$P_{18}$ : In the event of key contact employee turnover in a vendor firm, from the customer's perspective, satisfaction with the procedures used in the transition to the replacement employee will be directly related to the vendor firm providing the customer with a planned transition period.

The emphasis on the procedures used in the transition from the key contact employee to the replacement is consistent with current literature on how customers respond to any perceived failure on the part of the firm (Tax, Brown, and Chandrashekaran 1998). Customers pay as much attention to procedural justice issues or the way any recovery efforts are handled as they pay to distributive justice issues or what the recovery efforts deliver (Greenberg 1986). When an employee leaves on good terms, planned transitions between the old and new employees may be easier. When the employee leaves on bad terms, the firm may need to work harder to keep the customer satisfied. This is especially important because customers may perceive a badly handled transition as evidence that the vendor's management is poor or that the vendor does not really value the customer's business.

\section{Results for Research Question 2: Strategies to Retain Key Contact Employee Knowledge}

Because our emphasis was on what vendor firms can do in the event of key contact employee turnover, our focus was on examining how to retain employee knowledge, not how to retain employees. ${ }^{1}$ Retaining the knowledge a key contact employee possesses, even if the employee cannot be retained, was a key concern for respondents. In the words of a customer service manager at a Fortune-100 company,

If the company uses the exceptional individual employee as a role model and gets that employee to train everyone else, customers won't worry so much about relying on that particular individual to get superior service.

As shown in Table 1, five themes emerged from the depth interviews and surveys regarding strategies to retain key contact employee knowledge. Retention of employee knowledge was thought to be greater when firms fostered a culture of sharing, performance appraisal and reward systems encouraged information sharing, employees trusted the firm, technology was in place for sharing information, and organizational structures facilitated the sharing of information. We organized these five themes into three groups: firms valuing employees' information (culture of sharing), employees' motivation to share information, and employees' ability to share information.

\section{Valuing Employees' Information (Culture of Sharing)}

Respondents frequently mentioned the lack of awareness among vendor firms that employees possessed valuable information that could and should be retained. In an interview with the president of a vendor company, this lack became apparent:

I am constantly amazed at how little employee knowledge is used in making key decisions. It is as though most management directors have forgotten everything taught in Marketing 101. Companies don't seem to even recognize that it is important to know what your employees know.

Respondents also suggested that the failure to value employee information comes through when firms do little to foster a culture that emphasizes sharing this information. Across the board, a culture of sharing emerged as the most important indicator of whether employees believed firms genuinely recognized the value of employee information and whether employees would share information, as is shown in the following observation from a senior HR executive at one of the big three insurance companies:

I don't think the top management of our company has seriously thought about capturing the information that our employees have. Nobody talks about it. It is not part of any orientation or training programs. We have turnovers and

'Strategies to build employees' commitment to their own organization and enhance employee retention have been studied extensively in the management literature (see Allen and Meyer 1990; Gould 1979; Lee and Maurer 1997). 
promotions, and each time, it is the same. The new person has to start over, trying to figure out what customers want, or how to get things done. I'm sure if the company asked, many of our people would share the information, gladly! But, nobody has ever asked them! It is not part of the culture.

Proposition. Other researchers also have suggested that a culture of sharing is an important determinant of the effectiveness of efforts to capture employee information (Caylor 1999; Phillips 1997). Therefore, we offer the following proposition:

$P_{19}$ : The employee's willingness to share information with the vendor firm is directly related to the degree to which the vendor firm fosters a culture of sharing.

\section{Employee Motivation to Share Information}

As interviewees described how a culture of sharing is created, it became apparent that employee motivation to share information plays a key role. The executive vice president of HR for a Fortune-500 company discussed the reason employees might withhold information:

If I am the top performer in the company, why would I want to share? If I share my information, I used to be a top performer, and now, I am down to average. Granted the overall company average may be up, but what's in it for me?

Therefore, firms must give their star performers incentives to share their secrets for success with their supervisors, who would then pass them on to all of the employees. In discussing how to motivate employees, respondents mentioned performance appraisals and reward systems in their firm, as well as the trust engendered by the firm.

Performance appraisal and reward systems. The comments of several respondents emphasized the role of performance appraisals and reward systems in encouraging employees to share information. According to the director of sales at an industrial goods manufacturer,

To use a sports metaphor, you can't just reward the guy who makes the baskets. You have to reward and recognize the guy who makes the assists, who sets up the baskets for other people. People who share information with others in the company are setting up other people's baskets and should be rewarded.

A senior partner of a nationally known consulting firm had a different perspective:

Our company wants consultants to share the information they acquire about customers or about effective processes throughout the organization. But what is my incentive? The company's reward system is based on billable, chargeable hours. Any time I take to share information with my colleagues is not billable, chargeable time.... If the firm makes it clear that sharing information with the company is a critical element of performance, it is more likely to encourage this behavior.

Respondents commented that the rewards for information sharing need not be monetary. In our depth interview with the HR director of a pharmaceutical company, we learned that this firm had found that employees were more motivated to share information on what made them effective when they were given proper credit. Therefore, throughout the firm, "tips" on various aspects of dealing with customers were posted by specific employees. According to the HR director, by displaying these ideas in highly visible places, with authorship suitably acknowledged, the firm was able to institutionalize more of the individual employees' insights. The significance of both monetary and nonmonetary rewards also has been acknowledged in the literature on perceived organizational support for sharing (Barker and Camarata 1998).

Trust and commitment. Respondents suggested that an impediment to employees' motivation to share information was fear about how that information would be used. The director of sales training at a large consumer packaged goods company suggested that employees' trust in the firm is critical to motivate employees to share the information about their customers:

\begin{abstract}
We used to have required information sharing. We required people to report on customers and maintain detailed logs of their activities. We quickly learned that rather than reporting what they were doing, our people were reporting what they thought the managers wanted to see. Once we were able to get them to trust that we would not use the information against them and that turning in an honest report would not hurt them, we did not have to require information sharing-people saw the benefits and were more motivated to share accurate and complete information.
\end{abstract}

Propositions. When key contact employees trust the firm and are committed to it, they are more likely to share information with the firm voluntarily (Butler 1999; Morgan and Hunt 1994; Rousseau and Tijoriwala 1999). It is imperative that the key contact employees be assured that the vendor firm will not use any of the information they provide to put their jobs at risk. It is also necessary for the employee to feel committed to the firm, such that he or she is motivated to improve its well-being. Hunt and Morgan (1994) show that commitment leads to supportive behaviors such as altruism, conscientiousness, and lower intention to quit. On the basis of this discussion, we propose that

$P_{20}$ : An employee's willingness to share information with the vendor firm is directly related to the degree to which the vendor firm's performance appraisal and reward systems explicitly recognize and reward such behavior.

$P_{21}$ : An employee's willingness to share information with the vendor firm is directly related to the degree to which the employee trusts the vendor firm and is committed to it.

\section{Employee Ability to Share Information}

Even if employees are motivated to share information, they cannot unless the work environment enables them to do so easily and efficiently. Respondents suggested that two strategies were important in cultivating employee ability to share information: the use of technology as an enabling device and the creation of organizational structures to enhance the ability to share.

Technology. Vendor firms increasingly are relying on technology to make it easy for individual key contact employees to share information (Hunsaker and Lixfield 1999). According to the senior vice president of marketing at a major consumer promotions company, 
We have an extensive network/system to compile data. Through all these sources, we seek to give our marketing service consultants a leg up on the competition and provide them with a significant marketing advantage. In addition, we put in place a contact management system within Microsoft Outlook to manage customer touch points to record client contact names, hobbies, birthdays, etc. This system is a two-way system that can be accessed by management, internal personnel, and even other consultants.

Requiring the employee to record relevant customer information immediately helps the firm transform itself into a "learning organization" (Senge 1990) and improve the process of learning (Sinkula 1994). Given the ease and affordability of most data management systems, the key to competitive advantage is no longer whether a firm has such a system but how well the firm deploys the system. The critical question is what kind of information should be recorded to avoid information glut (Shenk 1997).

Organizational structures. Respondents presented several ideas on organizational structures that dealt with employees' ability to share information. One refers to the use of transitions. In our previous discussion of procedures to manage a changeover, we presented respondents' insights into the use of transitions. In discussing methods to capture employee information, respondents again referred to transitions as a valuable strategy. For example, a sales representative for a national beverage company talked about his experience with transitions:

One thing the company did was to have the new sales rep ride along with the old rep so that we could counsel them on the things they needed to look for, what each store manager's personality was like, and provide any suggestions for dealing with them. This made it a lot easier and a lot more natural to share information than to put stuff down in memos or something.

A variation on transitions that was mentioned was the use of backups and support staff. The remarks of the president of a high-tech company illustrate this point:

\begin{abstract}
Encourage a backup process where each individual has a backup person(s) who can fill in for them, if needed. In preparing to step in for each other, they act as understudies for the show. It makes it easier for the people to share information, because they know they have to step into each other's shoes to serve the customer. Another thing we do at our company is have a support staff for the customer contact employees. The creation of a support team for each such person makes the sharing of contact information much easier.
\end{abstract}

Propositions. On the basis of this discussion, we propose that

$P_{22}$ : An employee's likelihood of sharing information with the vendor firm is directly related to the amount of technology in place to support information sharing.

$P_{23}$ : An employee's likelihood of sharing information with the vendor firm is directly related to the degree to which organizational structures are in place to support information sharing.

These propositions deal with extracting information from employees. Vendor firms must recognize that this is not the same as ensuring that the information collected is put to use. The use of information is beyond the purview of this article, though it has been addressed in the marketing literature (e.g., Moorman, Zaltman, and Deshpandé 1992).

\section{Implications and Directions for Further Research}

Business-to-business interactions rely on a nexus of relationships: between the customer and the vendor firm's key contact employee, between the customer and the vendor firm, and between the vendor firm and its key contact employee. In Study 1, we examined what customers valued in key contact employees and what their concerns were when key contact employee turnover caused a disruption in the customer-employee relationship. In Study 2, we proposed solutions that vendor firms can use to address customers' concerns through the management of the customerfirm relationship and the firm-employee relationship. Through focus groups; depth interviews; and surveys of business-to-business customers, key contact employees, and managers, we developed a series of propositions. The implications of these two studies are discussed next.

\section{Managerial Implications}

From a managerial perspective, this research offers several useful insights into the drivers of customer relationship value. Examining a customer's relationship to the vendor firm versus the customer's relationship to the key contact employee should provide important information to firms about the dynamics of customer relationships and about who really owns the customer relationship.

When the customer's relationship to the vendor firm is weak and the relationship to the employee is strong, the greatest vulnerability lies in the firm's relationship with the customer. The customer perceives the key contact employee as the critical value driver. This frequently occurs when the customer cannot separate the deliverable from the employee (e.g., the creativity of the advertising campaign and the creative lead), the product delivered is a nonbranded commodity (e.g., raw material), or the product can be customized by several firms (e.g., made-to-order specialty chemicals). In these cases, the competitive advantage and differentiation may come from the relationship the customer has with the individual contact employee and the customer's belief that the employee knows the customer's business. Vendor firms in these settings should try to create additional sources of differentiation by offering more services, emphasizing their corporate citizenship, creating multiple links to the firm, and so forth. For example, although ACNielsen consultants have strong relationships with packaged goods companies, the firm also builds relationships with these customers by offering state-of-the-art systems that the consultants use to analyze data. These systems form structural bonds that bolster the relational bonds (Berry and Parasuraman 1991).

In addition, consider the situation in which the customer's relationship with the vendor firm is strong and the relationship with the employee is perceived by the customer to be less critical. One example would be a customer business development representative for Procter \& Gamble who calls on a particular customer. The value associated with Procter \& Gamble, the vendor, may be so strong that it 
lessens the importance of the customer's relationship with the specific key contact employee; there is lower firm vulnerability to employee turnover. Structural bonds that firms develop with customers, such as investment in compatible technologies (Berry and Parasuraman 1991), and financial bonds that tie customers to firms, such as key customer discounting programs, may create situations of this sort as well. Vendor firms in this situation should not ignore the employee-customer relationship but should investigate whether enhancing the value of all of their employees increases the total relationship value for customers.

In some situations, the relationships with both the vendor firm and the key contact employee may be significant contributors to the customer's relationship value. Customers that work with specific consultants from McKinsey \& Company may exhibit strong loyalty to both the firm and their specific lead consultant. This is a very positive outcome for the firm as long as the key contact employee continues to serve the customer. However, the firm should recognize its potential vulnerability if the individual employee were to leave or be transferred or promoted and thus be unable to serve the customer. Employees with strong personal ties to customers are employees that the firm should make great efforts to retain. Because turnover is bound to occur, there should be efforts to capture the employees' knowledge about their customers to transfer this information to a replacement. Furthermore, the firm should make strong efforts to convey to customers the high quality of all of its employees because, by inference, a customer will extend this impression to any replacement employee. Vendor firms should also ensure that the customer is kept actively engaged in the transition process so that the procedures are well understood and satisfactory to the customer.

There are two important considerations as firms decide to implement the recommendations of this research. The first is the order of implementation. Whether to focus on mitigating negative customer responses to the loss of the key contact employee or on capturing employee information should be determined after a careful audit of the vendor firm's existing systems and culture. For example, the strategy of capturing employee information and sharing it widely among the firm's employees requires greater reliance on the cooperation of key contact employees than does the strategy of building direct firm ties to the customer. A vendor firm must have clear communication with its employees, build employee trust, and be confident of employees' support before launching a program of capturing employee information.

The second issue pertains to the synergy among the various strategies proposed. Because this article focuses on developing a broad perspective of the issues involved in customer relationships, we offered a series of propositions that examine the effects of various vendor firm actions. In measuring its performance on these various strategies, the firm must take a holistic view of managing customer-employee relationships (Bendapudi and Berry 1997; Bendapudi and Leone 2001; Czepiel 1990). A vendor firm should also be careful not to send mixed signals to its employees regarding these activities. A firm may install technology to facilitate easy sharing of information, but if the reward systems still are geared toward individual performance, there will be lit- tle impact on employee behavior. Alternatively, the use of rotation of key contact employees may have the positive effect of capturing employee information. It also may have the negative effect of increasing employee (customer) dissatisfaction if employees (customers) dislike being rotated through customers (employees).

\section{Theoretical Implications}

This article makes several important theoretical contributions. First, it focuses attention on an increasingly important and rarely studied marketplace phenomenon, the impact of the turnover of a key contact employee. As Doney and Cannon (1997) note, few studies simultaneously examine customers' relationships with employees and the firms these employees represent. Furthermore, the studies that address this problem examine ongoing as opposed to discontinued relationships. This is the first research to provide both an empirical investigation of the phenomenon and a conceptual framework with research propositions to examine the impact of the loss of one of these relationships, the customers' link to the employee, on the customers' evaluation of the second relationship, the link to the vendor firm.

Second, our research goes beyond current work in business-to-business relationships, as well as in consumer relationships, that has focused on identifying characteristics of employees that are conducive to relationship formation. We go beyond such main effect predictions to understand situational factors that could moderate customers' responses to employee loss. The discussion of the perceived criticality of employees and the acceptability of replacement employees addresses the importance and uniqueness of the employee as a resource to the customer and an asset to the firm. The discussion of the procedures used in the changeover complements previous work on procedural justice in organizations. To the extent that the firm is viewed as having failed the customer by not retaining the employee, the findings of this study corroborate the importance of procedural issues in problem resolution (Tax, Brown, and Chandrashekaran 1998).

Third, our discussion of the sharing of information by the employee with the firm is a departure from many of the traditional areas of information sharing studied in the literature. For example, studies have focused on the sharing of information between vendors and customers (Cannon and Perreault 1999), between collaborators in alliances (Simonin 1997), and between market researchers and users (Moorman, Zaltman, and Deshpandé 1992). There is a crucial distinction between the focus of our study and other efforts to study information sharing. When employees share information with the firm, they are indirectly sharing this information with other employees, or with their potential replacements. Given that the incentive structures in most firms are tied to employees' relative performance, this is tantamount to sharing information with competitors. In this respect, employees may view information sharing as going beyond typical organizational citizenship behavior, because unlike other civic behavior, information sharing may threaten their position and compensation.

Finally, this article secures the perspectives of customers, key contact employees, and managers on key contact employee turnover through focus groups, depth interviews, and open-ended surveys. Such triangulation of 
multiple perspectives across multiple data collection methods contributes to a richer understanding of the phenomenon (Peñaloza 2000).

\section{Directions for Further Research}

Our study opens several avenues for further research. Consider the literature on celebrity endorsements that has demonstrated a rub-off from the endorser to the brand (Agrawal and Kamakura 1995). Such endorsements are assumed to work because they increase the marginal value of ad expenditures by creating brand equity through the "secondary association" of a celebrity with a brand (Keller 1993). Given the customer's simultaneous relationships to the employee and the vendor firm, it might be hypothesized that a similar process takes place in that evaluations of the employee may affect evaluations of the firm. This rub-off effect from the employee to the firm may be facilitated or inhibited by the attributions customers make about the employee's demeanor and behavior. Attribution literature suggests that customers may make attributions about the locus, stability, and controllability of an event (Bitner 1990; Weiner 1985). If customers attribute the employee's demeanor and behavior to an internal locus, factors intrinsic to the employee, there may be less rub-off from the employee to the firm. Conversely, if the customer believes that the behavior is stable across the firm's employees, the rub-off to the firm may be greater. The rub-off effect may also be greater if the customer believes that the firm controls the employee's demeanor and action. For example, a firm that hires on the basis of empathy or rewards empathy controls the dimension even if the locus is internal to the employee.

Furthermore, exploring customers' perspectives of these issues may lead to a richer understanding of key constructs. For example, we discuss the acceptability of replacement employees as though it were a discrete variable - that is, the employee is either acceptable or not. In reality, there may be a zone of tolerance for the acceptability of the replacement employee, and understanding the organizational, customer, and situational factors that affect acceptability would be a useful extension. Research also is needed to examine situations in which a customer team is involved rather than a single buyer. The use of a customer team may have a significant impact on responses to employee loss and the attributions that are made.

The focus of this article is how a vendor firm can manage its relationships with customers most effectively. Additional research should address how individual employees might respond to these efforts. Research also is needed to understand the employees' perspectives of the problem and comparable strategies that employees may use to ensure that they have strong ties to customers. This is consistent with recent calls to employees to be more proactive in managing their careers (Bridges 1998). Customers' responses to these initiatives also must be addressed.

\section{REFERENCES}

Agrawal, Jagdish and Wagner A. Kamakura (1995), "The Economic Worth of Celebrity Endorsers: An Event Study Analysis," Journal of Marketing, 59 (3), 56-62.

Allen, N.J. and I.P. Meyer (1990), "The Measurement and Antecedents of Affective, Continuance, and Normative Commitment to the Organization," Journal of Occupational Psychology, 9 (1), 1-18.

Anderson, Erin and Thomas S. Robertson (1995), "Inducing Multiline Salespeople to Adopt House Brands," Journal of Marketing, 59 (2), 16-31.

Anderson, John R. (1983), The Architecture of Cognition. Cambridge, MA: Harvard University Press.

Baker, William E. and James M. Sinkula (1999), "The Synergistic Effect of Market Orientation and Learning Orientation on Organizational Performance," Journal of the Academy of Marketing Science, 27 (4), 411-27.

Barker, Randolph T. and Martin R. Camarata (1998), "The Role of Communication in Creating and Maintaining a Learning Organization: Preconditions, Indicators, and Disciplines," Journal of Business Communication, 35 (4), 443-67.

Barnes, James G. (1997), "Closeness, Strength, and Satisfaction: Examining the Nature of Relationships Between Providers of Financial Services and Their Retail Customers," Psychology \& Marketing, 14 (8), 765-90.

Barney, Jay B. (1991), "Firm Resources and Sustained Competitive Advantage," Journal of Management, 17 (1), 99-120.

Barone, Michael J., Anthony D. Miyazaki, and Kimberly A. Taylor (2000), "The Influence of Cause-Related Marketing on Consumer Choice: Does One Good Turn Deserve Another?" Journal of the Academy of Marketing Science, 28 (2), 248-62.

Beatty, Sharon E., Morris Mayer, James E. Coleman, Kristy Ellis Reynolds, and Jungki Lee (1996), "Customer-Sales Associate Retail Relationships," Journal of Retailing, 72 (3), 223-47.
Bendapudi, Neeli and Leonard L. Berry (1997), "Customers' Motivations for Maintaining Relationships with Service Providers," Journal of Retailing, 73 (1), 15-37.

- and Robert P. Leone (2001), "How to Lose Your Star Performer-Without Losing Your Customers Too," Harvard Business Review, 79 (November), 104-12.

Berry, Leonard L. and A. Parasuraman (1991), Marketing Services. New York: The Free Press.

Bitner, Mary Jo (1990), "Evaluating Service Encounters: The Effects of Physical Surroundings and Employee Responses," Journal of Marketing, 54 (2), 69-82.

Bridges, William (1998), Creating You and Co. Reading, MA: Addison Wesley.

Brown, Stephen W. and Teresa A. Swartz (1989), "A Gap Analysis of Professional Service Quality," Journal of Marketing, 53 (2), 92-98.

Brown, Steven P. (1995), "The Moderating Effects of Insupplier/ Outsupplier Status on Organizational Buyer Attitudes," Journal of the Academy of Marketing Science, 23 (3), 170-81.

Brown, Tom J. (1998), "Corporate Associations in Marketing: Antecedents and Consequences," Corporate Reputation Review, I (3), 215-33.

- and Peter A. Dacin (1997), "The Company and the Product: Corporate Associations and Consumer Product Responses," Journal of Marketing, 61 (1), 68-84.

Buss, Dale D. (1999), “Keep 'Em Coming Back," The Wall Street Journal, (April 19), 3.

Butler, John K. (1999), “Trust Expectations, InformationSharing, Climate of Trust, and Negotiation Effectiveness and Efficiency," Group and Organization Management, 24 (2), 217-38.

Calder, Bobby J. (1977), "Focus Groups and the Nature of Qualitative Marketing Research," Journal of Marketing Research, 14 (August), 353-64. 
Cannon, Joseph P. and William D. Perreault (1999), "Buyer-Seller Relationships in Business Markets," Journal of Marketing Research, 36 (November), 439-60.

Caylor, Peggy (1999), "Marcus and Millichap-Still Growing After All These Years," National Real Estate Investor, 41 (1), 44-45.

Chenet, Pierre, Caroline Tynan, and Arthur Money (1999), "Service Performance Gap: Re-evaluation and Redevelopment," Journal of Business Research, 46 (2), 133-47.

Cohen, Michael D. (1991), "Individual Learning and Organizational Routine: Emerging Connections," Organization Science, 2 (3), 135-39.

and Paul Bacdayan (1994), “Organizational Routines Are Stored as Procedural Memory: Evidence from a Laboratory Study," Organization Science, 5 (4), 554-68.

Cravens, David W. (1995), "The Changing Role of the Sales Force," Marketing Management, 4 (2), 48-57.

Crosby, Lawrence A., Kenneth R. Evans, and Deborah Cowles (1990), "Relationship Quality in Services Selling: An Interpersonal Influence Perspective," Journal of Marketing, 54 (3), $68-81$.

Czepiel, John A. (1990), "Service Encounters and Service Relationships: Implications for Research," Journal of Business Research, 20 (1), 13-21.

Deshpandé, Rohit (1983), “Paradigms Lost': On Theory and Method in Research in Marketing," Journal of Marketing, 47 (4), 101-10.

Dollinger, Marc J., Peggy A. Golden, and Todd Saxton (1997), "The Effect of Reputation on the Decision to Join a Joint Venture," Strategic Management Journal, 18 (2), 127-40.

Doney, Patricia M. and Joseph P. Cannon (1997), "An Examination of the Nature of Trust in Buyer-Seller Relationships," Journal of Marketing, 61 (2), 35-51.

Duboff, Rob and Carla Heaton (1999), "Employee Loyalty: A Key Link to Value Growth," Strategy \& Leadership, 27 (1), 8-13.

Dwyer, F. Robert, Paul H. Schurr, and Sejo Oh (1987), "Developing Buyer-Seller Relationships," Journal of Marketing, 51 (2), 11-27.

Easterby-Smith, Mark (1997), "Disciplines of Organizational Learning: Contributions and Critiques," Human Relations, 50 (9), 1085-113.

Glaser, Barney, and Anselm Strauss (1967), The Discovery of Grounded Theory. Chicago: Aldine.

Gould, Sam (1979), "An Equity-Exchange Model of Organizational Involvement," Academy of Management Review, 4 (1), 53-62.

Greenberg, Jerald (1986), "Determinants of Perceived Fairness of Performance Evaluations," Journal of Applied Psychology, 71 (2), $340-42$.

Gronroos, Christian (1995), "Relationship Marketing: The Strategy Continuum," Journal of the Academy of Marketing Science, 23 (4), 252-54.

Gwinner, Kevin P., Dwayne D. Gremler, and Mary Jo Bitner (1998), "Relational Benefits in Services Industries: The Customer's Perspective," Journal of the Academy of Marketing Science, 26 (2), 101-14.

Hammond, Sue Annis and John W. Slocum Jr. (1996), "The Impact of Prior Firm Financial Performance on Subsequent Corporate Reputation," Journal of Business Ethics, 15 (2), 159-65.

Handelman, Jay M. and Stephen J. Arnold (1999), "The Role of Marketing Actions with a Social Dimension: Appeals to the Institutional Environment," Journal of Marketing, 63 (3), 33-48.

Hannon, John M. and George T. Milkovich (1996), "The Effects of Human Resource Reputation Signals on Share Prices: An Event Study," Human Resource Management, 35 (3), 405-24.

Howard, Carole M. (1998), "How Your Employee Communications Programs Can Boost Productivity and Pride," Public Relations Quarterly, 43 (3), 15-23.

Hunsaker, J. Russell and George E. Lixfield (1999), "How Technology Improves Team Effectiveness," The Journal for Quality and Participation, 22 (3), 30-33.
Hunt, Shelby D. (1983), Marketing Theory. Homewood, IL: Richard D. Irwin.

- and Robert M. Morgan (1994), "Organizational Commitment: One of Many Commitments or Key Mediating Construct?" Academy of Management Journal, 37 (6), 1568-87.

Jones, Eli, Jesse N. Moore, Andrea J.S. Stanaland, and Rosalind A.J. Wyatt (1998), "Salesperson Race and Gender and the Access and Legitimacy Paradigm: Does Difference Make a Difference?" Journal of Personal Selling \& Sales Management, 28 (4), 71-88.

Keaveney, Susan M. (1995), "Customer Switching Behavior in Service Industries: An Exploratory Study, Journal of Marketing, 59 (April), 71-82.

Keller, Kevin Lane (1993), "Conceptualizing, Measuring, and Managing Customer-Based Brand Equity," Journal of Marketing, 57 (January), 1-28.

Kohli, Ajay and Bernard J. Jaworski (1990), "Market Orientation: The Construct, Research Propositions, and Managerial Implications," Journal of Marketing, 54 (April), 1-18.

Lahti, Ryan K. and Michael M. Beyerlein (2000), "Knowledge Transfer and Management Consulting: A Look at "The Firm," Business Horizons, 43 (1), 65-74.

Lee, Thomas W. and Steven D. Maurer (1997), "The Retention of Knowledge Workers with the Unfolding Model of Voluntary Turnover," Human Resource Management Review, 7 (3), 247-75.

Leuthesser, Lance (1997), "Supplier Relational Behavior: An Empirical Assessment," Industrial Marketing Management, 26 (3), 245-54.

Lovett, Steve, David Harrison, and Meghna Virick (1997), "Managing the Boundary Spanner-Customer Turnover Connection," Human Resource Management Review, 7 (4), 405-24.

Lukas, Bryan A. and O.C. Ferrell (2000), "The Effect of Market Orientation on Product Innovation," Journal of the Academy of Marketing Science, 28 (2), 239-47.

Macintosh, Gerrard and Lawrence S. Lockshin (1997), "Retail Relationships and Store Loyalty: A Multi-level Perspective," International Journal of Research in Marketing, 14 (5), 487-97.

Maignan, Isabelle, O.C. Ferrell, and G. Tomas Hult (1999), "Corporate Citizenship: Cultural Antecedents and Business Benefits," Journal of the Academy of Marketing Science, 27 (Fall), 455-69.

McCracken, Grant (1988), The Long Interview. Newbury Park, CA: Sage Publications.

Moorman, Christine, Rohit Deshpandé, and Gerald Zaltman (1993), "Factors Affecting Trust in Market Research Relationships," Journal of Marketing, 57 (1), 81-101.

- and Anne S. Miner (1997), "The Impact of Organizational Memory on New Product Performance and Creativity," Journal of Marketing Research, 34 (1), 91-107.

$\longrightarrow$ and - (1998), "Organizational Improvisation and Organizational Memory," The Academy of Management Review, 23 (October), 698-723.

__ Gerald Zaltman, and Rohit Deshpandé (1992), "Relationships Between Providers and Users of Market Research," Journal of Marketing Research, 29 (3), 314-28.

Morgan, Robert M. and Shelby D. Hunt (1994), "The Commitment-Trust Theory of Relationship Marketing," Journal of Marketing, 58 (3), 20-38.

Peñaloza, Lisa (2000), "The Commodification of the American West: Marketers' Production of Cultural Meanings at the Trade Show," Journal of Marketing, 64 (October), 82-109.

Petrick, Joseph A., Robert F. Scherer, James D. Brodzinski, John F. Quinn, and M. Fall Ainina (1999), "Global Leadership Skills and Reputational Capital: Intangible Resources for Sustainable Competitive Advantage," Academy of Management Executive, 13 (1), 58-69.

Pfeffer, Jeffrey, Toru Hatano, and Timo Santalainen (1995), "Producing Sustainable Competitive Advantage Through People," Academy of Management Executive, 9 (February), 55-72. 
Phillips, Tim (1997), "Talking of the Intranet," Director, 51 (4), 62-66.

Pilling, Bruce K. and Sevo Eroglu (1994), “An Empirical Examination of the Impact of Salesperson Empathy and Professionalism and Merchandise Salability on Retail Buyers' Evaluations," Journal of Personal Selling \& Sales Management, 14 (Winter), 45-58.

Price, Linda L. and Eric J. Arnould (1999), "Commercial Friendships: Service Provider-Client Relationships in Context," Journal of Marketing, 63 (4), 38-56.

Reynolds, Kristy E. and Sharon E. Beatty (1999), "A Relationship Customer Typology," Journal of Retailing, 75 (4), 509-24.

Rousseau, Denise and Snehal A. Tijoriwala (1999), "What's a Good Reason to Change? Motivated Reasoning and Social Accounts in Promoting Organizational Change," Journal of Applied Psychology, 84 (4), 514-28.

Ruth, Julie A., Cele C. Otnes, and Frederic F. Brunel (1999), "Gift Recipient and the Reformulation of Interpersonal Relationships," Journal of Consumer Research, 25 (4), 385-402.

Seabright, Mark A., Daniel A. Levinthal, and Mark Fichman (1992), "Role of Individual Attachments in the Dissolution of Organizational Attachments," Academy of Management Journal, 35 (1), 122-60.

Senge, Peter M. (1990), The Fifth Discipline: The Art and Practice of the Learning Organization. New York: Doubleday.

Shenk, David (1997), "Data Smog: Surviving the Info Glut," MIT's Technology Review, 100 (4), 18-26.

Simonin, Bernard L. (1997), "The Importance of Collaborative Know-How: An Empirical Test of the Learning Organization," Academy of Management Journal, 40 (5), 1150-74.

Singleton, Ruth (1997), "No Fine for Leaving," National Law Journal, (June 23), A4.

Sinkula, J.M. (1994), "Market Information Processing and Organizational Learning," Journal of Marketing, 58 (1), 35-45.

Slater, Derek (1998), "Storing the Mind, Minding the Store," $\mathrm{ClO}$ Enterprise Magazine, 11 (9), 1-9.

Smith, Mark A. and H. Millard Smith (1997), "Physician Selling: What Physicians Want from a Salesperson," Health Industry Today, 60 (2), 9-14.

Solomon, Michael R. (1985), "Packaging the Service Provider," Services Industries Journal, 5 (2), 64-71.

Stafford, Jan (1998), "The Battle over Intellectual Property," VAR Business, (November 9), 18.
Stanley, Thomas J. (1985), "Profiling the Affluent Credit User," The Bankers Magazine, 168 (1), 53-60.

Tax, Stephen S. and Stephen W. Brown (1998), "Recovering and Learning from Service Failure," Sloan Management Review, 40 (1), 75-88.

- - and Murali Chandrashekaran (1998), "Customer Evaluations of Service Complaint Experiences: Implications for Relationship Marketing," Journal of Marketing, 62 (2), 60-76.

Thompson, Craig J. (1997), "Interpreting Consumers: A Hermeneutical Framework for Deriving Marketing Insights from the Texts of Consumers' Consumption Stories," Journal of Marketing Research, 34 (4), 438-55.

, William Locander, and Howard R. Pollio (1989), "Putting Consumer Experience Back into Consumer Research: The Philosophy and Method of Existential Phenomenology," Journal of Consumer Research, 16 (2), 133-47.

- Howard R. Pollio, and William Locander (1994), "The Spoken and the Unspoken: A Hermeneutic Approach to Understanding the Cultural Viewpoints that Underlie Consumers' Expressed Meanings," Journal of Consumer Research, 21 (3), 432-52.

Weiner, Bernard (1985), "An Attributional Theory of Achievement Motivation and Emotion," Psychological Review, 92 (4), 548-73.

Weitz, Barton A. and Kevin D. Bradford (1999), "Personal Selling and Sales Management: A Relationship Marketing Perspective," Journal of the Academy of Marketing Science, 27 (2), 241-54.

and Sandy D. Jap (1995), "Relationship Marketing and Distribution Channels," Journal of the Academy of Marketing Science, 23 (4), 305-20.

Workman, John P., Jr., Christian Homburg, and Kjell Gruner (1998), "Marketing Organization: An Integrative Framework of Dimensions and Determinants," Journal of Marketing, 62 (3), $21-41$.

Yoon, Eunsang, Hugh J. Guffey, and Valerie Kijewski (1993), "The Effects of Information and Company Reputation on Intentions to Buy a Business Service," Journal of Business Research, 27 (3), 215-28.

Zinn, Walter and A. Parasuraman (1997), "Scope and Intensity of Logistics-Based Strategic Alliances," Industrial Marketing Management, 26 (2), 137-47. 